\title{
SYNTHESIS AND ANTIMICROBIAL EVALUATION OF SOME NOVEL SULFONYLAMIDO-BENZOXAZOLES
}

\author{
Ozlem Temiz-Arpaci, ${ }^{1}$ * Fatma DoĞanc, ${ }^{1}$ Duygu SaC, ${ }^{1}$ Elmas Sari, ${ }^{1}$ \\ FATMA KAYNAK-ONURDAG ${ }^{2}$ and SUZAN OKTEN ${ }^{2}$ \\ ${ }^{1}$ Faculty of Pharmacy, Department of Pharmaceutical Chemistry, Ankara University, \\ 06100, Tandogan, Ankara, Turkey \\ ${ }^{2}$ Faculty of Pharmacy, Department of Pharmaceutical Microbiology, Trakya University, \\ 22030, Edirne, Turkey
}

(Received: February 20, 2015; accepted: June 9, 2015)

\begin{abstract}
A series of 2-( $p$-substituted phenyl)-5-[(4-substituted phenyl) sulfonylamido]-benzoxazoles were synthesized and tested for their antimicrobial activities. The structures of the new derivatives were elucidated by spectral techniques. The minimum inhibitory concentrations (MIC) of the new benzoxazoles were determined against standard bacterial and fungal strains and drug-resistant isolates and compared to those of several reference drugs.
\end{abstract}

Keywords: Benzoxazole - sulfonylamides - antibacterial activity - antifungal activity - synthesis

\section{INTRODUCTION}

The treatment of infectious diseases still remains to be an important and challenging problem due to emerging infectious diseases and increasing number of multi-drug resistant microbial pathogens $[3,13]$. In spite of the large number antibiotics and chemotherapeutics, the emergence of old and new antibiotic resistant bacterial strains constitutes a substantial need for the new class of potent antimicrobial agents $[4,11]$.

Heterocyclic compounds play an important role in designing a new class of structural entities of medicinal importance with new mechanisms of action. Benzoxazoles, structural isosteres of natural nucleotides that can interact with biopolymers, constitute an important class of heterocyclic compounds with antimicrobial and antifungal activity $[1-2,9,12,14-17]$.

A benzoxazole derivative; calcimycin is a carboxylic polyether antibiotic from a strain of Streptomyces chartreusis (NRRL 3882). It was found to be very active against Gram-positive bacteria including some Bacillus, Micrococcus strains [12]. Routiennocin, 3-hydroxy-11,15-desmethyl analog of calcimycin and cezomycin, 3-demethylamino analog of calcimycin are found to be highly active against Bacillus cereus, B. negaterium, Micrococcus luteus and Streptomyces rimosus [14]. Additionaly frankamide; 11-demethyl cezomycin is another calcimycin analogue which has activ-

*Corresponding author; e-mail address: temiz@pharmacy.ankara.edu.tr 
ity against B. subtilis, Staphylococcus aureus, Enterococcus faecalis and against several plant pathogenic fungal strains [9].

In the last years we described the synthesis of different derivatives of some 2,5-disubstituted benzoxazoles and the results of assays on their in vitro antimicrobial activity against some Gram-positive, Gram-negative bacteria and fungus Candida albicans [1-2, 15-17]. In the present study, we report a new series of 2-( $p$-substituted phenyl)-5-[(4-substituted phenyl) sulfonylamido]-benzoxazoles. 2-19 has been synthesized using a two-step procedure. Several control drugs and new synthesized benzoxazole compounds were evaluated for their antibacterial and antifungal activity against standard strains and their drug-resistant isolates.<smiles>[R]c1ccc(-c2nc3cc(N)ccc3o2)cc1</smiles><smiles>[R]c1ccc(C(=O)Nc2ccc3oc(-c4ccc([R])cc4)nc3c2)cc1</smiles>

Fig. 1. Synthesis of compounds $\mathbf{2}-\mathbf{1 9}$

\section{MATERIALS AND METHODS}

\section{Chemistry}

Chemicals and solvents were purchased from Sigma-Aldrich (Munich, Germany) and Fisher Scientific (Pittsburgh, PA, USA), and used without further purification. Silica gel $\mathrm{HF}_{254}$ chromatoplates $(0.3 \mathrm{~mm})$ were used for thin layer chromatography, and chloroform was employed as mobile phase. Melting points were recorded on a Stuart Scientific SMP 1 instrument (Bibby Scientific Limited, Stone, Staffordshire, UK) and are uncorrected. NMR spectra were recorded on a Varian Mercury $400 \mathrm{MHz}$ NMR 
spectrometer (Palo Alto, CA, USA) in $\mathrm{CDCl}_{3}$; tetramethylsilane (TMS) was used as an internal standard. The mass spectra were recorded on a Waters ZQ Micromass LC-MS spectrometer (Milford, MA, USA) using the ESI(+) method. Elemental analyses were performed on an LECO 932 CHNS instrument (St. Joseph, MI, USA), and results were within $\pm 0.4 \%$ of theoretical values. For the synthesis of compounds (2-19) firstly, 5-amino-2-( $p$-substituted phenyl)-benzoxazoles (1a-c) were synthesized by heating 2,4-diaminophenol with $p$-substituted benzoic acid in polyphosphoric acid (PPA). Then compounds 2-19 were obtained by treating a solution of p-substituted-benzenesulfonyl chlorides with 5-amino-2-( $p$-substituted phenyl)-benzoxazoles $(\mathbf{1} \mathbf{a}-\mathbf{c})[1,10]$. All the compounds $\mathbf{2}-\mathbf{1 9}$ were prepared as new products. The structures of new benzoxazole derivatives (Fig. 1) were confirmed by their ${ }^{1} \mathrm{H} /{ }^{13} \mathrm{C}-\mathrm{NMR}$, Mass and elementary analysis (Table 1 ).

\section{Microbiological assay}

Materials used in the microbiology study were Mueller Hinton Agar (MHA) (Merck, Darmstadt, Germany), Mueller Hinton Broth (MHB) (Merck), Sabouraud Dextrose Agar (SDA) (Merck), Sabouraud Liquid Medium (SLM) (Merck) and RPMI-1640 medium with L-glutamine (Sigma) buffered $\mathrm{pH} 7$ with 3-[N-morpholino]propansulfonic acid (MOPS) (Sigma) were used for microbial cultures. Standard powders of ampicillin (Mustafa Nevzat İlaç Sanayii), cefuroxime (Mustafa Nevzat İlaç Sanayii), ciprofloxacin (Fluka), imipenem (Fluka), meropenem (AstraZeneca), fluconazole (Sigma) and amphotericin B (Riedel de Haen, Seelze) were used as standard antimicrobial agents. Microorganisms used in the assay were; Escherichia coli ATCC 25922, Pseudomonas aeruginosa ATCC 27853, Staphylococcus aureus ATCC 29213, Enterococcus faecalis ATCC 29212 and Candida albicans ATCC 10231 standard strains and clinical isolates provided from Trakya University Health Center for Medical Research and Practice (Edirne, Turkey) were used in the study.

For microbiological assays, stock solutions of the test compounds were prepared in DMSO. Antibiotic solutions were prepared according to the guideline of CLSI M100-S18. Antimicrobial susceptibility testing was performed through CLSI M100-S18 [5] and CLSI M27-A3 [6] directions. Bacterial isolates were subcultured in MHA plates and incubated over night at $37^{\circ} \mathrm{C}$ and C. albicans was subcultured in SDA plates at $35^{\circ} \mathrm{C}$ for $24-48 \mathrm{~h}$. The microorganisms were passaged at least twice to ensure purity and viability. Pure colonies were transferred to MHB and SLM for bacteria and fungi, respectively. They were incubated in the appropriate conditions overnight. After incubation, the bacterial suspensions used for inoculation were prepared at $10^{5} \mathrm{CFU} / \mathrm{mL}$ by diluting fresh cultures at MacFarland 0.5 density $\left(10^{7} \mathrm{CFU} /\right.$ $\mathrm{mL}$ ). Yeast suspensions were also prepared according to McFarland 0.5 density and a working suspension was made by a $1: 100$ dilution followed by a $1: 20$ dilution of the stock suspension $\left(2.5 \times 10^{3} \mathrm{CFU} / \mathrm{mL}\right)$. Susceptibility testing was performed with MHB for bacteria and RPMI-1640 medium with L-glutamine buffered pH 7 with MOPS for fungi. The solution of the newly synthesized compounds and standard 


\begin{tabular}{|c|c|c|c|c|c|c|}
\hline \multirow{8}{*}{ 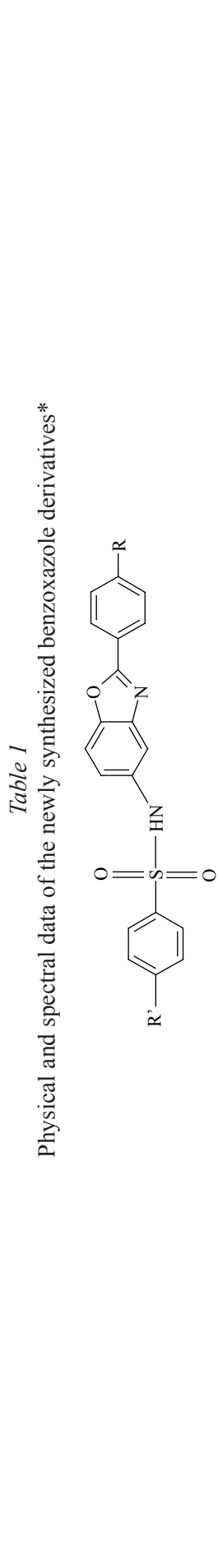 } & 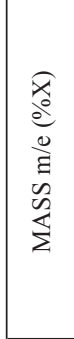 & 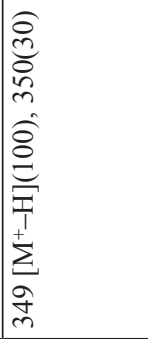 & 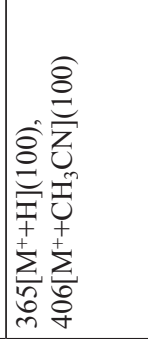 & 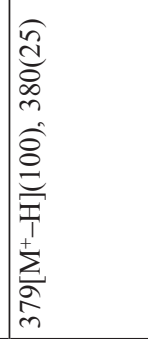 & 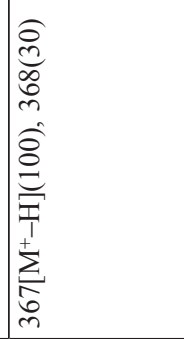 & 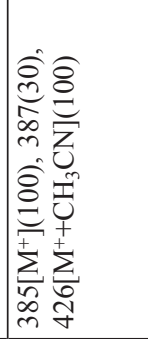 \\
\hline & 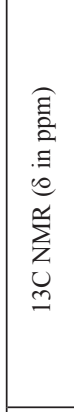 & 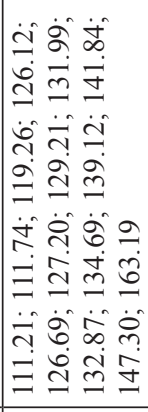 & 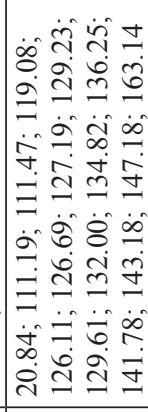 & 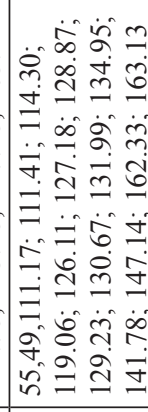 & 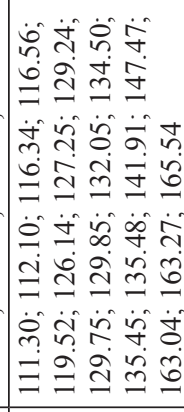 & 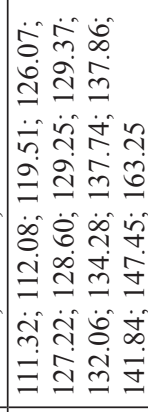 \\
\hline & 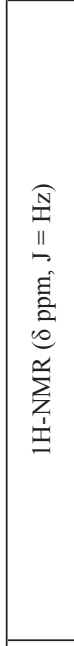 & 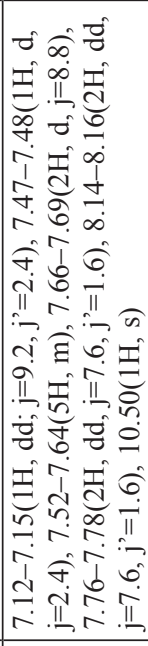 & 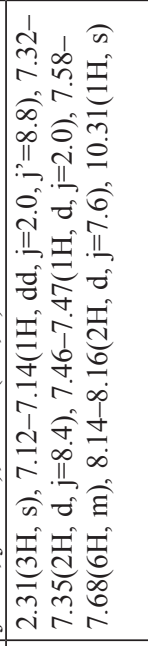 & 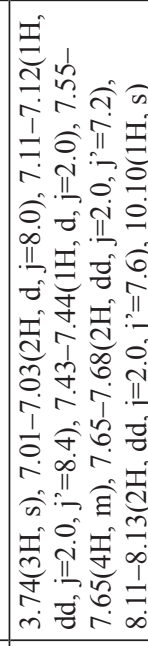 & 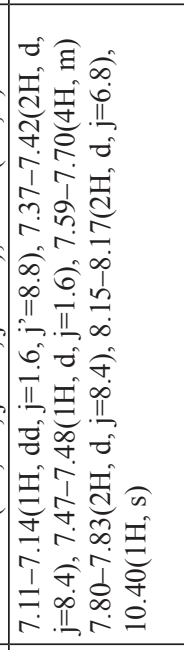 & 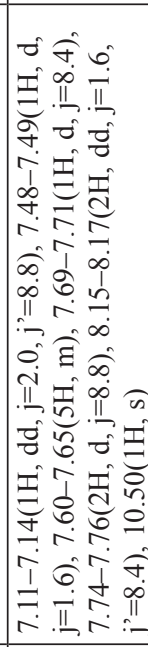 \\
\hline & $\frac{\pi}{0} \stackrel{0}{0}$ & I & $\approx$ & $\tilde{\infty}$ & in & in \\
\hline & $\begin{array}{l}0 \\
0 \\
0 \\
\Sigma \\
\Sigma\end{array}$ & 咅 & $\frac{\tilde{\infty}}{\underline{1}}$ & \begin{tabular}{l}
$\widehat{c}$ \\
$\frac{1}{2}$ \\
\multicolumn{2}{c}{}
\end{tabular} & 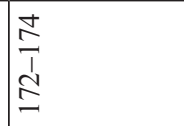 & $\begin{array}{l}\underset{N}{N} \\
\underset{\sim}{\sim}\end{array}$ \\
\hline & $\approx$ & $I$ & 㞼 & 籴 & II & $\vec{U}$ \\
\hline & $\simeq$ & \pm & \pm & \pm & \pm & \pm \\
\hline & 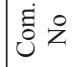 & $\stackrel{*}{*}$ & $m$ & $\nabla$ & in & 6 \\
\hline
\end{tabular}




\begin{tabular}{|c|c|c|c|c|c|c|c|}
\hline 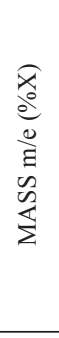 & 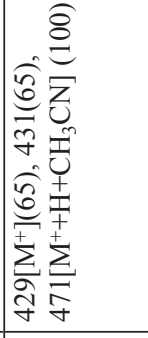 & 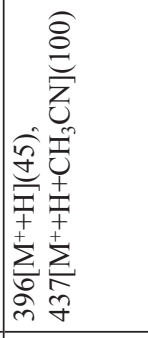 & 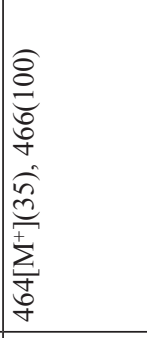 & 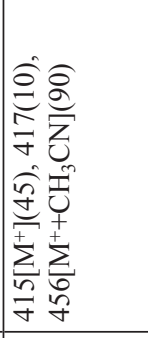 & 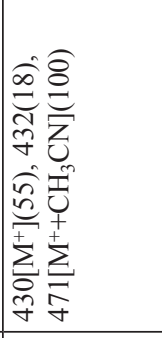 & 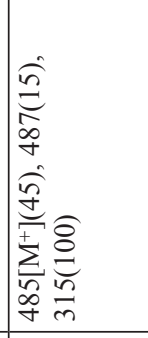 & 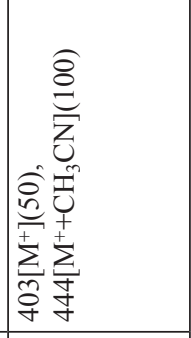 \\
\hline 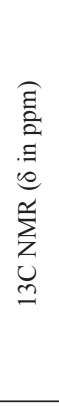 & 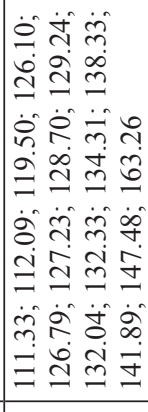 & 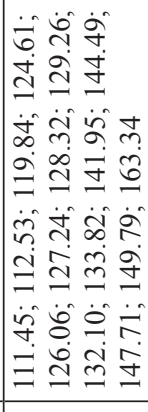 & 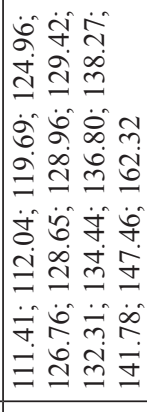 & 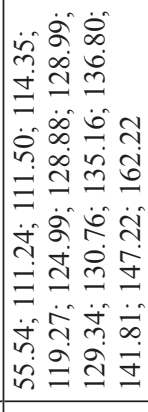 & 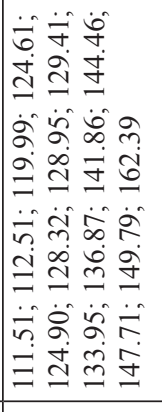 & 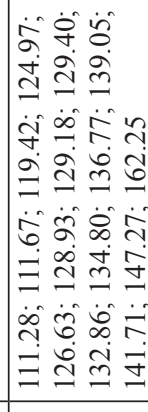 & 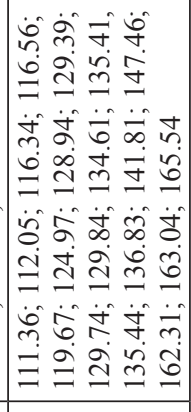 \\
\hline 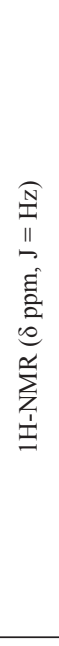 & 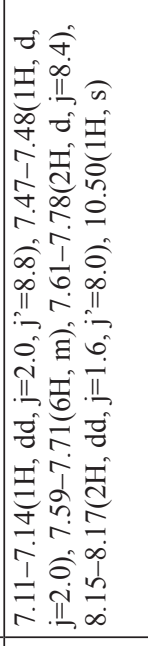 & 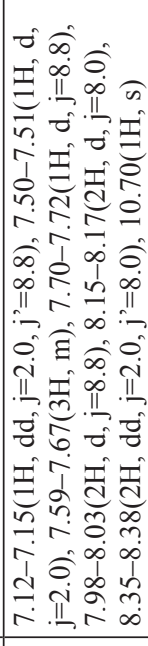 & 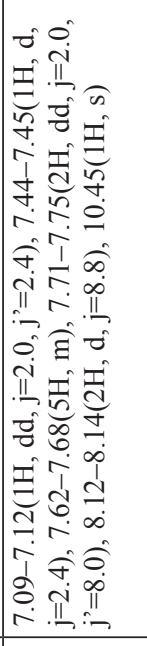 & 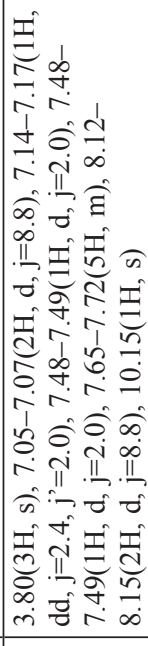 & 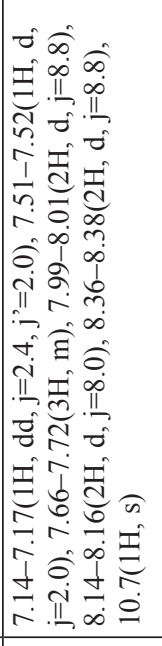 & 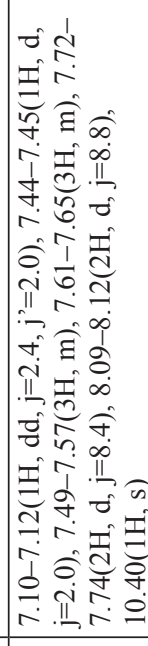 & 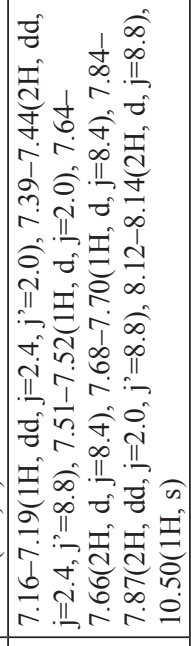 \\
\hline 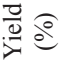 & m & $\approx$ & \pm & F & 囬 & $\vec{\sim}$ & $\cong$ \\
\hline $\begin{array}{l}0 \\
0 \\
0 \\
\dot{0}\end{array}$ & $\begin{array}{l}\overrightarrow{\widehat{N}} \\
\text { ते } \\
\text { ते }\end{array}$ & 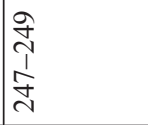 & 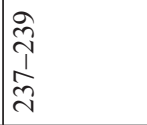 & 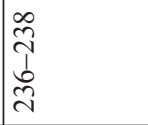 & $\begin{array}{l}8 \\
\stackrel{8}{0} \\
\text { ì } \\
\text { N }\end{array}$ & $\begin{array}{l}\infty \\
\tilde{N} \\
\hat{N} \\
\hat{\sim}\end{array}$ & $\begin{array}{l}\overrightarrow{\hat{N}} \\
\stackrel{i}{\sim} \\
\vec{v}\end{array}$ \\
\hline$\approx$ & $\ddot{m}$ & $\overbrace{}^{2}$ & $\ddot{\oplus}$ & : & $\overbrace{}^{0}$ & $\Psi$ & I \\
\hline$\simeq$ & \pm & $\mp$ & $\vec{v}$ & $\vec{v}$ & $\bar{U}$ & $\bar{U}$ & $\vec{U}$ \\
\hline$\tilde{\Xi}$ & $r$ & $\infty$ & $a$ & 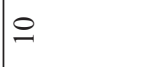 & $=$ & $\simeq$ & $\cong$ \\
\hline
\end{tabular}




\begin{tabular}{|c|c|c|c|c|c|c|}
\hline 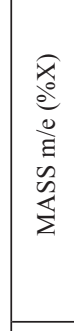 & 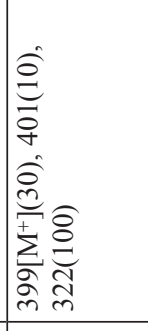 & 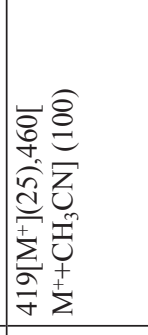 & 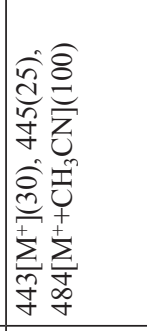 & 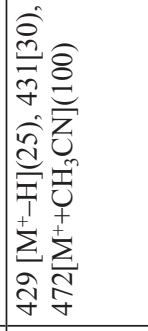 & 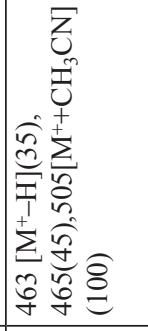 & 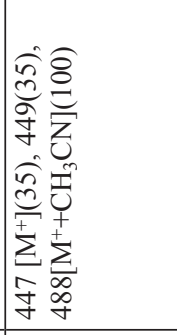 \\
\hline 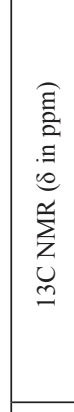 & 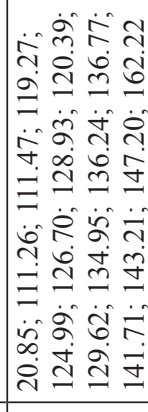 & 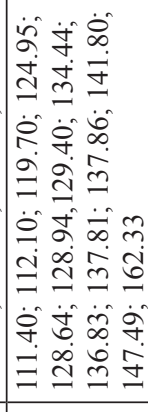 & 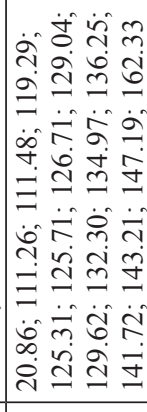 & 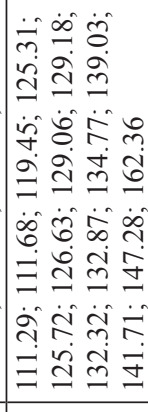 & 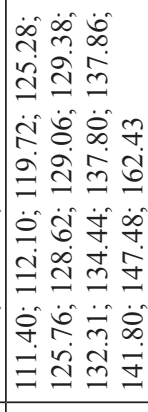 & 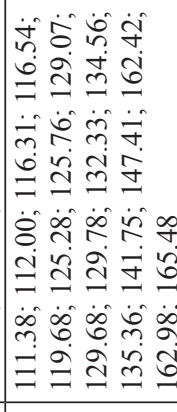 \\
\hline 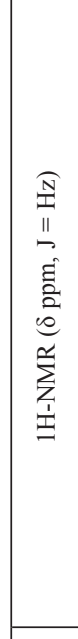 & 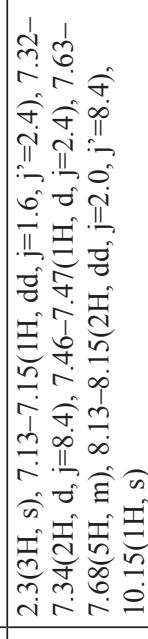 & 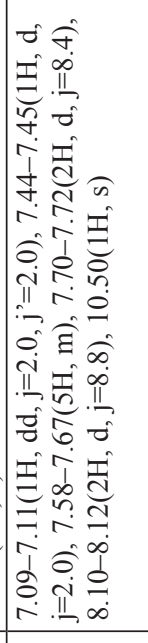 & 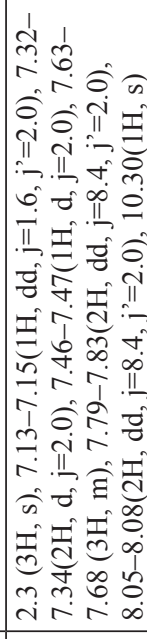 & 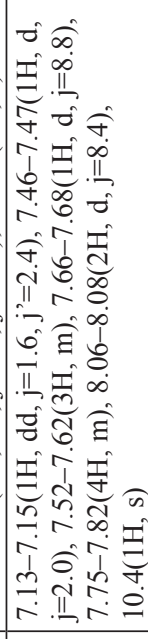 & 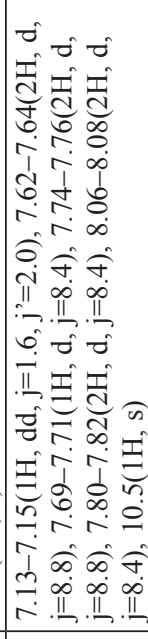 & 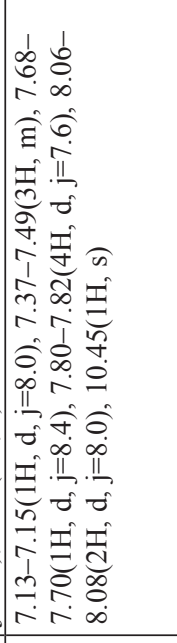 \\
\hline$\frac{0}{2} \stackrel{0}{0}$ & $\hat{\imath}$ & $\stackrel{\infty}{i n}$ & 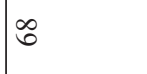 & $\infty$ & 8 & $\approx$ \\
\hline 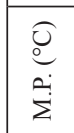 & $\begin{array}{l}\frac{n}{N} \\
\underset{\sim}{N}\end{array}$ & 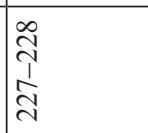 & 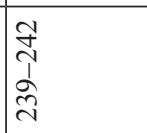 & $\begin{array}{l}\tilde{\lambda} \\
\hat{n} \\
\hat{\sim}\end{array}$ & 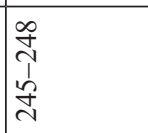 & 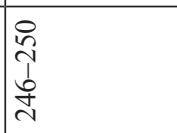 \\
\hline$\approx$ & త్ర & J & తึ & II & $\bar{U}$ & I \\
\hline$\simeq$ & $\bar{U}$ & J & $\ddot{\varphi}$ & 崩 & $\ddot{n}$ & $\ddot{\Phi}$ \\
\hline$\tilde{g}^{ \pm \prime z}$ & \pm & $\because$ & $\stackrel{0}{0}$ & $=$ & $\infty$ & 2 \\
\hline
\end{tabular}


drugs were prepared at 1024, 512, 256, 128, 64, 32, 16, $8 \mu \mathrm{g} / \mathrm{mL}$ and $16,8,4,2,1$, $0.5,0.25,0.125 \mu \mathrm{g} / \mathrm{mL}$ concentrations, respectively, by diluting the stock concentrations with a multichannel pipette.

After dilution, a $10 \mu \mathrm{L}$ bacterial or fungal inoculum was added to each well of the microdilution trays. The trays were incubated at $37{ }^{\circ} \mathrm{C}$ for bacteria and $35{ }^{\circ} \mathrm{C}$ for fungi, in a humid chamber and MIC endpoints were read after $24 \mathrm{~h}$ of incubation. The lowest concentration of the compound that completely inhibits macroscopic growth was determined and minimum inhibitory concentrations (MICs) were reported. All organisms were tested in triplicate in each run of the experiments. Solvents, pure microorganisms and pure media were used as control wells.

\section{RESULTS}

The desired benzoxazole derivatives were synthesized using a two-step procedure. Firstly, 5-amino-2-( $p$-substituted phenyl)-benzoxazoles were synthesized by heating 2,4-diaminophenol with $p$-substituted benzoic acid in polyphosphoric acid (PPA). Then compounds $\mathbf{2 - 1 9}$ were obtained by treating a solution of $p$-substituted-benzenesulfonyl chlorides with 5-amino-2-( $p$-substituted phenyl)-benzoxazoles as shown in Fig. 1.

Their structures were elucidated with Mass, ${ }^{1} \mathrm{H}$ NMR and ${ }^{13} \mathrm{C}$ NMR spectroscopy. Their purity was analyzed through elemental analysis that was within $\pm 0.4 \%$ of theoretical values. Physical and spectral data of the synthesized benzoxazole derivatives are given in Table 1. In the ${ }^{1} \mathrm{H}$ NMR spectra of the compounds (2-19) of the signal of the $\mathrm{NH}$ proton was observed at $10.70-10.10 \mathrm{ppm}$ as a singlet band, aromatic $\mathrm{OCH}_{3}$ protons were observed at 3.74-3.80 as singlet band for compounds 4, 10. Aromatic $\mathrm{CH}_{3}$ protons appeared at 2.31-2.30 ppm as singlet band for compounds $\mathbf{3 , 1 4}, \mathbf{1 6}$. Besides all the aromatic protons were observed at the expected regions. On the other hand, mass spectra of the compounds showed $\mathrm{M}^{+}+\mathrm{H}, \mathrm{M}^{+}, \mathrm{M}^{+}-\mathrm{H}$ peaks, since the electrospray ionization method was employed, in accordance with their formulas. Additionally, ${ }^{13} \mathrm{C}$ NMR spectra of compounds were evaluated.

All the newly synthesized benzoxazoles (2-19) and standard drugs were evaluated for their antimicrobial activity against some Gram-positive, Gram-negative bacteria and fungus $C$. albicans and their drug-resistant isolates. The results are presented in Table 2 .

\section{DISCUSSION}

In the last few years, we described the synthesis of some 2,5-disubstituted-benzoxazoles and the results of assays on their in vitro antimicrobial activity against some Gram-positive, Gram-negative bacteria, along with the microfungus C. albicans and their isolates [1, 2, 15-17]. 
In this study, our goal was to investigate the role of different ( $p$-substituted-pheny) sulfonylamido groups on the $5^{\text {th }}$ position of $2-(p$-substituted phenyl)benzoxazole ring as potential antimicrobial agents. According to Table 2, compounds 2-19 exhibited broad antibacterial activity with MIC values of $64-1024 \mu \mathrm{g} / \mathrm{mL}$. $256-512 \mu \mathrm{g} / \mathrm{mL}$ against $S$. aureus and the MRSA isolate. All MRSA strains are known to be resistant to penicillins, cephalosporins, cephems and other beta-lactam antibiotics, regardless

Table 2

In vitro antimicrobial activities of the newly synthesized benzoxazole derivatives in comparison with control drugs (MIC in $\mu \mathrm{g} / \mathrm{mL}$ )

\begin{tabular}{|c|c|c|c|c|c|c|c|c|c|c|}
\hline Comp. No. & E.c. & E.c.* & P.a. & P.a.* & S.a. & S.a.* & E.f. & E.f.* & C.a. & C.a.* \\
\hline 2 & 128 & 128 & 128 & 128 & 256 & 256 & 128 & 128 & 64 & 64 \\
\hline 3 & 1024 & 1024 & 512 & 1024 & 512 & 1024 & 1024 & 1024 & 1024 & 1024 \\
\hline 4 & 1024 & 1024 & 1024 & 1024 & 1024 & 1024 & 1024 & 1024 & 1024 & 1024 \\
\hline 5 & 256 & 256 & 32 & 128 & 512 & 512 & 256 & 256 & 128 & 128 \\
\hline 6 & 512 & 1024 & 1024 & 1024 & 512 & 512 & 512 & 512 & 1024 & 1024 \\
\hline 7 & 512 & 1024 & 1024 & 1024 & 512 & 512 & 512 & 1024 & 1024 & 1024 \\
\hline 8 & 256 & 1024 & 1024 & 1024 & 512 & 512 & 1024 & 1024 & 1024 & 1024 \\
\hline 9 & 1024 & 1024 & 1024 & 1024 & 512 & 512 & 512 & 1024 & 1024 & 1024 \\
\hline 10 & 1024 & 1024 & 512 & 1024 & 512 & 512 & 512 & 1024 & 1024 & 1024 \\
\hline 11 & 512 & 256 & 1024 & 1024 & 512 & 512 & 1024 & 512 & 1024 & 1024 \\
\hline 12 & 512 & 1024 & 1024 & 1024 & 512 & 512 & 1024 & 512 & 1024 & 1024 \\
\hline 13 & 512 & 512 & 1024 & 1024 & 512 & 512 & 1024 & 1024 & 1024 & 1024 \\
\hline 14 & 512 & 1024 & 1024 & 1024 & 512 & 512 & 1024 & 1024 & 1024 & 1024 \\
\hline 15 & 512 & 1024 & 1024 & 1024 & 512 & 256 & 512 & 1024 & 1024 & 1024 \\
\hline 16 & 1024 & 512 & 1024 & 1024 & 512 & 512 & 512 & 1024 & 1024 & 1024 \\
\hline 17 & 1024 & 1024 & 1024 & 1024 & 512 & 512 & 512 & 1024 & 1024 & 1024 \\
\hline 18 & 1024 & 1024 & 1024 & 1024 & 512 & 1024 & 1024 & 1024 & 1024 & 1024 \\
\hline 19 & 1024 & 1024 & 1024 & 1024 & 512 & 1024 & 1024 & 1024 & 1024 & 1024 \\
\hline Ampicillin & 2 & $>16$ & - & - & 0.5 & $>16$ & 0.5 & $>16$ & - & - \\
\hline Cefuroxime & 8 & $>16$ & - & - & 0.5 & $>16$ & - & $>16$ & - & - \\
\hline Ciprofloxacin & $<0.125$ & $>16$ & 0.25 & $>16$ & 0.25 & $>16$ & 1 & $>16$ & - & - \\
\hline İmipenem & 0.25 & 0.25 & 1 & $>16$ & $<0.125$ & $>16$ & 1 & $>16$ & - & - \\
\hline Meropenem & $<0.125$ & $<0.125$ & 1 & 8 & $<0.125$ & - & 2 & - & - & - \\
\hline Fluconazole & - & - & - & - & - & - & - & - & 1 & 64 \\
\hline $\begin{array}{l}\text { Ampho- } \\
\text { thericin B }\end{array}$ & - & - & - & - & - & - & - & - & 0.25 & 2 \\
\hline
\end{tabular}

E.c. - Escherichia coli ATCC 25922; E.c.* - Escherichia coli isolate; P.a. - Pseudomonas aeruginosa ATCC 27853; P.a.* - Pseudomonas aeruginosa isolate; S.a. - Staphylococcus aureus ATCC 29213; S.a.* - Staphylococcus aureus isolate (MRSA); E.f. - Enterococcus faecalis ATCC 29212; E.f.* - Enterococcus faecium isolate (VRE); C.a. - Candida albicans ATCC 10231. All isolates are resistant to ciprofloxacin. 
of susceptibility testing results. Beta-lactams should not be reported as susceptible for MRSA, even if tested as susceptible in vitro because beta-lactam breakpoints pose a risk for reporting MRSA isolates as falsely susceptible [7]. So, no higher concentrations of ampicillin, cefuroxime and imipenem may be active against the studied MRSA strain. Through this knowledge and our results; all derivatives had lower antibacterial activity against the standard strain of $S$. aureus; however making a comparison for MRSA isolate, in this respect, is not possible.

The newly synthesized compounds exhibited antibacterial activities with MIC values between $128-1024 \mu \mathrm{g} / \mathrm{mL}$ against $E$. faecalis and E. faecium VRA isolate. According to the breakpoints of the agents for enterococci, the VRE isolate used in this study is also resistant to ampicillin, ciprofloxacin and imipenem [8]. The compound 2 was found as the most potent derivative with a MIC value of $128 \mu \mathrm{g} / \mathrm{mL}$ against $E$. faecalis and E. faecium VRA isolate.

All the newly synthesized benzoxazole derivatives exhibited antibacterial activity against the Gram-negative bacteria $E$. coli and $P$. aeruginosa and their respective drug-resistant isolates, with MIC values between 128 and $1024 \mu \mathrm{g} / \mathrm{mL}$, except for derivative 5, which was the most effective compound against $P$. aeruginosa with a MIC value of $32 \mu \mathrm{g} / \mathrm{mL}$. Thus, the compound having a phenyl group at position 2 of the benzoxazole ring and having a $p$-fluorophenylsulfonylamido group at position 5 of the benzoxazole ring showed a stronger activity against $P$. aeruginosa than that having $p$-chloro and/or $p$-bromophenyl group at position 2 of benzoxazole ring. However, all the compounds possessed low antibacterial activity against tested Gramnegative bacteria in comparison with standard drugs. The tested compounds (2-19) displayed antifungal activity against $C$. albicans and its isolate with MIC values between 128 and $1024 \mu \mathrm{g} / \mathrm{mL}$. They displayed low antifungal activity in comparison with the antifungal reference drugs fluconazole and amphotericin B.

In this study, we aimed to develop new effective antimicrobial agents possessing benzoxazole nuclei in their structure. Benzoxazole derivatives 2-19 as a new class of synthetic antimicrobial agents along with their in vitro antimicrobial activity tested against some Gram-negative, Gram-positive bacteria, and its isolate and C. albicans and its isolate. So that we put a para-substituted-phenyl sulfonylamido moiety on fifth position and different $p$-substituted phenyl groups on second position of benzoxazole ring for increasing the antimicrobial activity. Nevertheless, the benzoxazole derivatives were found to possess a broad spectrum of antimicrobial activity with MIC values of 32-1024 $\mu \mathrm{g} / \mathrm{mL}$ and the standard drugs were more active against the tested pathogens. According to the results, the new compounds needed high concentrations to be active against the microorganisms. In this case, it is advisable to do further work in order to determine whether there is a synergistic effect of the new compounds with the reference antibiotics.

\section{ACKNOWLEDGEMENTS}

This work was supported by the Ankara University Research Fund (Grant No 12L 3336001). The Central Laboratory of the Faculty of Pharmacy, Ankara University, Turkey supported the acquisition of the NMR and mass spectra and elemental analyses in this work. 


\section{REFERENCES}

1. Arisoy, M., Temiz-Arpaci, O., Yildiz, I., Kaynak-Onurdag, F., Aki, E., Yalcin, I., Abbasoglu, U. (2008) Synthesis, antimicrobial activity and QSAR studies of 2,5-disubstituted benzoxazoles. SAR QSAR Environ. Res. 19, 589-612.

2. Arisoy, M., Temiz-Arpaci, O., Kaynak-Onurdag, F., Ozgen, S. (2012) Synthesis and antimicrobial activity of novel benzoxazoles. Z. Naturforsch. 67C, 466-472.

3. Betts, A., Kaltz, M. O., Hochberg, M. E. (2013) Back to the future: evolving bacteriophages to increase their effectiveness against the pathogen Pseudomonas aeruginosa PAO1. Evol. Appl. 6, $1054-1063$.

4. Chopra, I. (2013) The 2012 Garrod lecture: Discovery of antibacterial drugs in the 21 st century. J. Antimicrob. Chemother. 68, 496-505.

5. CLSI (2008) Performance standards for antimicrobial susceptibility testing; 16th informational supplement, CLSI M100-S18. Clinical and Laboratory Standards Institute, Wayne, PA, USA.

6. CLSI (2006) Reference method for broth dilution antifungal susceptibility testing yeast; approved standard, M27-A3. Clinical and Laboratory Standards Institute, Wayne, PA, USA.

7. Dien Bard, J., Hindler, J. A., Gold, H. S., Limbago, B. (2014) Rationale for eliminating Staphylococcus breakpoints for $\beta$-lactam agents other than penicillin, oxacillin or cefoxitin, and ceftaroline. Clin. Infect. Dis. 58, 1287-1296.

8. European Committee on Antimicrobial Susceptibility Testing Breakpoint tables for interpretation of MICs and zone diameters Version 5.0, valid from 2015-01-01, Available at: http://www.eucast.org/ clinical_breakpoints (2015-25-03, date last accessed).

9. Haansuu, J. P., Klika, K. D., Söderholm, P. P., Ochaveranko, V. V., Pihlaja, K., Haahtela, K. K., Vuorela, P. M. (2001) Isolation and biological activity of frankiamide. J. Ind. Microbiol. Biotechnol. 27, 62-66.

10. Kato, T., Okamato, I., Tanatani, A., Hatano, T., Uchiyama, M., Kagechika, H., Masu, H., Katagiri, K., Tominaga, M., Yamaguchi, K., Azumaya, I. (2006) Spontaneous resolution of aromatic sulfonamides: Effective screening method and discrimination of absolute structure. Org. Lett. 8, 5017-5020.

11. Moustafa, M. A., Gineinah, M. M., Nasr, M. N., Bayoumi, W. A. (2004) Novel analogues of sydnone: synthesis, characterization and antibacterial evaluation. Arch. Pharm. (Weinheim) 337, 427-433.

12. Prudhomme, M., Guyot, J., Jeminet, G. (1986) Semi-synthesis of A23187 (calcimycin) analogs. IV. Cation carrier properties in mitochondria of analogs with modified benzoxazole rings. Antimicrobial activity. J. Antibiot. (Tokyo) 39, 934-937.

13. Radulovic, N. S., Blagojevic, P. D., Stojanovic-Radic, Z. Z., Stojanovic, N. M. (2013) Antimicrobial plant metabolites: structural diversity and mechanism of action. Curr. Med. Chem. 20, 932-952.

14. Sarma, H. K., Sharma, B. K., Tiwari, S. C. (2003) A novel calcimycin antibiotic from Gram-positive actinomycete Frankia microsymbiont. Curr. Sci. 85, 1401-1403.

15. Temiz-Arpaci, O., Aki-Sener, E., Yalçin, I., Altanlar, N. (2002) Synthesis and antimicrobial activity of some 2-[p-substituted-phenyl]benzoxazol-5-yl-arylcarboxyamides. Arch. Pharm. (Weinheim) 335, 283-288.

16. Temiz-Arpaci, O., Ozdemir, A., Yalçin, I., Yildiz, I., Aki-Sener, E., Altanlar, N. (2005) Synthesis and antimicrobial activity of some 5-[2-(morpholin-4-yl)acetamido] and/or 5-[2-(4-substituted piperazin1-yl)acetamido]-2-(p-substituted phenyl)benzoxazoles. Arch. Pharm. (Weinheim) 338, 105-111.

17. Temiz-Arpaci, O., Eylem Cifcioglu Goztepe, B., Kaynak-Onurdag, F., Ozgen, S., Senol, F. S., Erdogan Orhan, I. (2013) Synthesis and different biological activities of novel benzoxazoles. Acta Biol. Hung. 64, 249-261.

18. Wynne, G. M., Wren, S. P., Johnson, P. D., Price, P. D., De Moor, O., Nugent, G., Storer, R., Pye, R. J., Dorgan, C. R. (2009) PCT Int. Appl. WO 2009019504 A1 20090212. 